The Journal of

Thoracic and Cardiovascular

Surgery

Vol 128, No. 5, November 2004

\title{
Emergency conversion to cardiopulmonary bypass during attempted off-pump revascularization results in increased morbidity and mortality
}

Nirav C. Patel, MD

Nilesh U. Patel, MD

Didier F. Loulmet, MD

John C. McCabe, MD

Valavanur A. Subramanian, MD

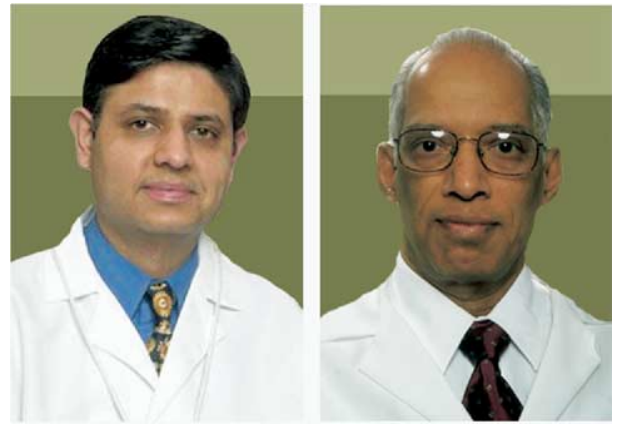

Patel and Subramanian (left to right)
Objective: We sought to evaluate outcomes and predictors of emergency conversion to cardiopulmonary bypass during attempted off-pump coronary bypass surgery.

Methods: From January 1999 through July 2002, 1678 consecutive isolated coronary artery bypass operations were performed at Lenox Hill Hospital, with the intention to treat all patients with off-pump coronary bypass surgery. Fifty $(2.97 \%)$ patients required urgent conversion to cardiopulmonary bypass. All the preoperative, intraoperative, and postoperative variables were collected and analyzed in accordance with the New York State Cardiac Surgery Reporting System. Multivariate regression analysis was performed to determine predictors for conversion.
From Lenox Hill Hospital, New York, NY. Read at the Eighty-third Annual Meeting of The American Association for Thoracic Surgery, Boston, Mass, May 4-7, 2003.

Received for publication April 22, 2003; revisions received April 19, 2004; accepted for publication April 26, 2004.

Address for reprints: Nirav C. Patel, MD, FRCS (C-Th), Section of Cardiothoraic Surgery, Lenox Hill Hospital, 130 E 77th St, 4th Floor, New York, NY 10021 (Email: niravcpatel@aol.com).

J Thorac Cardiovasc Surg 2004;128:655-61 $0022-5223 / \$ 30.00$

Copyright (C) 2004 by The American Association for Thoracic Surgery

doi:10.1016/j.jtcvs.2004.04.043
Results: In-hospital mortality and major morbidity were significantly lower in the nonconverted group compared with the converted patients (mortality: $1.47 \%$ [n $=$ $24]$ vs $12 \%[\mathrm{n}=6], P=.001$; stroke: $1.1 \%[\mathrm{n}=18]$ vs $6 \%[\mathrm{n}=3], P=.02$; renal failure: $1.23 \%[\mathrm{n}=20]$ vs $6 \%[\mathrm{n}=3], P=.02$; deep sternal wound infection: $1.54 \%[\mathrm{n}=25]$ vs $8 \%[\mathrm{n}=4], P=.009$; respiratory failure: $3.75 \%[\mathrm{n}=61]$ vs $28 \%$ [n $=14], P<.0001$; nonconverted vs converted patients, respectively). The annual incidence of conversion decreased during the study period. There was a significant reduction in the incidence of conversion after routine use of a cardiac positioning device to performing lateral and inferior wall grafts $(4.2 \%[\mathrm{n}=27] \mathrm{vs}$ $2.3 \%[\mathrm{n}=23], P=.04)$. None of the preoperative variables were independent predictors of conversion on multivariate regression analysis.

Conclusions: Because emergency conversion to cardiopulmonary bypass during attempted off-pump coronary bypass surgery results in significantly higher morbidity and mortality, studies comparing off-pump coronary bypass surgery with conventional coronary artery surgery should include converted patients in the off-pump group. In our experience, emergency conversion is an unpredictable event. The incidence of conversion decreases with increasing experience of surgeons in performing off-pump coronary surgery and use of a cardiac positioning device. 


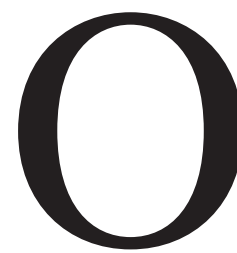

ff-pump coronary artery bypass surgery $(\mathrm{OPCAB})$ is being increasingly performed, and many reports have shown reduced in-hospital and short-term morbidity in comparison with conventional coronary bypass grafting performed during cardiopulmonary bypass (CPB). ${ }^{1-6}$ None of these reports mention emergency conversion to $\mathrm{CPB}$ during attempted OPCAB. The incidence of emergency conversion ranges from $0 \%$ to $22 \%$ in various reports. ${ }^{7-12}$ Outcomes in the converted patients have not been studied in detail, and neither have the predictors of conversion. The aim of this study was to evaluate outcomes and predictors of emergency conversion to CPB during attempted OPCAB.

\section{Patients and Methods \\ Patients}

From January 1999 through July 2002, 1678 consecutive isolated coronary bypass graftings were performed at the Lenox Hill Hospital with the intention to treat all patients with OPCAB. All patients included in the study underwent revascularization through a median sternotomy, including reoperative procedures.

\section{Emergency Conversion}

Emergency conversion was defined as use of CPB after the initial intent of performing OPCAB if the reason for using $\mathrm{CPB}$ was any of the following: hemodynamic compromise, hemorrhage, ischemic episodes, and cardiac arrest. We did include patients who had any of the above, even while manipulating the heart to assess the coronary anatomy. We did not include patients who underwent CPB semielectively because of coronary anatomy (diffusely diseased vessels, small-caliber vessels, and intramyocardial vessels).

\section{Methods}

Surgical technique of off-pump revascularization. All operations were performed through a median sternotomy. Conduits were harvested, and patients were partially heparinized to maintain the activated clotting time at approximately 300 seconds. Deep pericardial sutures, Trendelenburg position, and right tilt were used to facilitate exposure of the lateral, posterior, and inferior vessels of the heart. From June 2000 through July 2002, we used the apical suction cardiac positioning device Xpose (Guidant Corporation, Cupertino, Calif) in all cases to facilitate exposure.

During the study period, we used a compression stabilization system for performing distal anastomoses. During the construction of the anastomoses, target vessel hemostasis was obtained with intravascular shunts, proximal and distal silicone rubber (Silastic; Dow Corning, Midland, Mich) vessel loops, or both. A humidified carbon dioxide blower was used for better visualization.
Although the order of performing anastomoses was at the surgeon's discretion, the usual order was to perform the left internal thoracic artery anastomosis to the left anterior descending coronary artery first. Proximal anastomoses were performed either before or after distal anastomoses, depending on the situation and the operating surgeon's preference. Composite grafting, anastomotic connectors, clampless aortic seals, or a single application of the side-biting clamp on the aorta was used, depending on the condition of the ascending aorta and the coronary artery anatomy.

Conversion to CPB. When conversion to $\mathrm{CPB}$ was necessary after full heparinization, patients were started on $\mathrm{CPB}$ with an aortic cannula in the ascending aorta and a single 2-stage venous cannula in the right atrial appendage. The operation was then continued on the assisted beating heart or with aortic crossclamping with antegrade and retrograde cold blood cardioplegia per the surgeon's preference. In the event of cardiac arrest, cardiac massage was continued until full CPB was established.

\section{Data Collection and Outcome Analysis}

Patients were identified from the prospective computerized cardiac surgical registry maintained in accordance with the mandatory New York State Cardiac Surgery Reporting System guidelines. All the data entry was done by an independent data coordinator. Surgical reports of all the patients requiring $\mathrm{CPB}$ were reviewed, and intraoperative data were collected. Multivariate regression analysis was performed to identify the predictors of conversion. The factors used in the multivariate model were left ventricular ejection fraction, priority of the operation, reoperative surgery, class of angina, left main coronary stenosis, peripheral vascular disease, and use of a positioning device. The risk-adjusted mortality ratio was calculated according to the New York State Cardiac Surgery Reporting System model. The SPSS for Windows version 11.5 statistical package (SPSS, Inc, Chicago, Ill) was used to perform statistical analysis.

\section{Results}

\section{Incidence of Emergency Conversion}

The overall incidence of emergency conversion was $2.97 \%$ $(\mathrm{n}=50)$. The annual incidence of emergency conversions decreased from $4.8 \%(\mathrm{n}=16)$ to $3.8 \%(\mathrm{n}=19), 2.6 \%(\mathrm{n}=$ $13)$, and $0.7 \%(n=2)$ for the first to the fourth year of experience, respectively. There was a significant reduction in the incidence of conversion after the routine use of a cardiac positioning device while performing lateral and inferior wall grafts $(4.2 \%[\mathrm{n}=27 / 642]$ vs $2.3 \%[\mathrm{n}=$ 23/986], $P=.04$; Figure 1).

There were an additional 45 (2.8\%) patients undergoing elective conversion during the same period. The mortality and morbidity in electively converted patients was similar compared with those of nonconverted patients. 


\section{Preoperative Variables}

Data on preoperative variables are shown in Table 1. There were significantly higher numbers of patients with lower left ventricular ejection fraction; preoperative history of peripheral disease, cerebrovascular disease, or both; and previous myocardial infarction in the emergency converted patients compared with in the nonconverted patients. There was no significant difference in other major preoperative variables between the 2 groups.

\section{Operative Details of Conversions}

Timing and reasons for conversion (Table 2, A and $\boldsymbol{B})$. Of the 17 patients undergoing conversion during left anterior descending artery grafting, 2 of them had bleeding from a right ventricular injury, 5 had cardiac arrest caused by ischemia and ventricular fibrillation, 1 had embolization caused by coronary probing, 1 had air embolization into the coronary arteries from the left ventricle, and the rest had ischemia during the coronary artery occlusion.

Of the 18 patients requiring conversion during grafting of the circumflex artery and its branches, 8 had ischemiahypotension during positioning and vessel occlusion before arteriotomy, 4 had ischemia-hypotension during vessel grafting, 4 had cardiac arrest during vessel occlusion, and 2 had ischemia after completion of the grafts.

Of the 3 patients requiring conversion during the grafting of the right coronary artery and its branches, 1 had bradycardia followed by cardiac arrest during vessel grafting, 1 had bleeding from the right atrium and air embolism caused by a vessel loop, and 1 had ischemia during vessel occlusion.

Of the 2 patients requiring conversion because of the proximal anastomosis, 1 had bleeding from the anastomotic connector, and the other experienced an aortic dissection from a proximal anastomosis. Both patients required circulatory arrest to repair the aorta.

Five patients who required conversion before the coronary grafting was commenced experienced ischemia-hypotension during cardiac manipulation to assess the distal targets and placement of deep pericardial sutures.

All 5 patients requiring conversion after completion of bypass grafts had cardiac arrest, with the reasons being a short left internal thoracic artery, kinking of the right internal thoracic artery, right coronary vein graft thrombosis, air embolism (probably caused by injury to right atrium), and ventricular fibrillation in a patient with preoperative cardiogenic shock, respectively.

Cardiac arrest. Fifteen (30\%) patients had cardiac arrest requiring internal cardiac message, and the average time from arrest to establishing CPB was 7.6 minutes (range, 3-16 minutes). The time was longer in patients whose chests were being closed when cardiac arrest occurred.

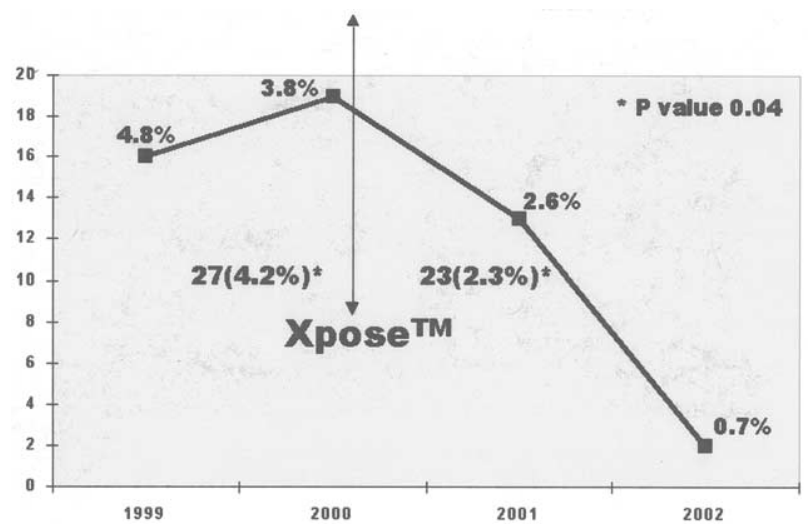

Figure 1. Reduced incidence of emergency conversion with time and use of the Xpose cardiac positioning device.

Additional operative details. Nineteen patients had bypass grafting completed on assisted-beating bypass grafting after commencing $\mathrm{CPB}$, whereas the other 31 patients had aortic crossclamping with cardioplegic arrest.

Only 1 of the 45 patients who had conversion to CPB related to ischemia or ventricular fibrillation had an intracoronary shunt used during vessel occlusion.

Of the 10 patients requiring additional procedures after conversion to $\mathrm{CPB}, 3$ had bypass grafts revised, 3 had additional bypass grafts performed to the coronary artery already grafted during $\mathrm{OPCAB}, 2$ required repair of the right ventricle, and 2 required a reparative procedure to the ascending aorta.

\section{Postoperative Outcomes}

As shown in Table 3, patients who required emergency conversion to $\mathrm{CPB}$ during attempted OPCAB had significantly higher major morbidities and in-hospital mortality compared with patients who did not need emergency conversion to $\mathrm{CPB}$.

\section{Predictors of Conversion}

As shown in Table 4, none of the preoperative variables was a significant predictor of emergency conversion to CPB during attempted OPCAB. Use of the cardiac positioning device (Xpose) was an independent factor in reducing conversion.

\section{Discussion}

Off-pump coronary artery surgery has been increasingly performed in the last few years, with improving cardiac stabilization devices and increased experience of the surgeons. However, use of CPB still remains the bailout procedure for patients undergoing attempted OPCAB. The incidence of conversion to $\mathrm{CPB}$ during the initial attempt at $\mathrm{OPCAB}$ remains very variable $(0 \%-22 \%)$, and so is the 
TABLE 1. Preoperative variables

\begin{tabular}{|c|c|c|c|}
\hline Variable & $\begin{array}{l}\text { Emergency conversion } \\
\qquad(\mathrm{n}=50)\end{array}$ & $\begin{array}{c}\text { OPCAB without } \\
\text { emergency } \\
\text { conversion }(n=1628)\end{array}$ & $P$ value \\
\hline Age, y (average [range]) & $67.6(37-84)$ & $66.2(26-92)$ & NS \\
\hline Female sex & $24.0 \%(n=12)$ & $27.6 \%(n=450)$ & NS \\
\hline Emergency surgery & $4.0 \%(n=2)$ & $3.3 \%(n=53)$ & NS \\
\hline Ejection fraction $<40 \%$ & $36 \%(n=18)$ & $22.9 \%(n=372)$ & .04 \\
\hline Left main stenosis $>50 \%$ & $38.0 \%(n=19)$ & $35.4 \%(n=576)$ & NS \\
\hline Class IV angina & $46.0 \%(n=23)$ & $37.1 \%(n=604)$ & NS \\
\hline Reoperative surgery & $8.0 \%(n=4)$ & $3.5 \%(n=57)$ & NS \\
\hline Peripheral and cerebrovascular disease & $48.0 \%(n=24)$ & $34.4 \%(n=560)$ & .05 \\
\hline Previous myocardial infarction & $22.0 \%(n=11)$ & $9.1 \%(n=148)$ & .005 \\
\hline Diabetes & $44.0 \%(n=22)$ & $38.5 \%(n=626)$ & NS \\
\hline Renal failure & $8.0 \%(n=4)$ & $6.9 \%(n=113)$ & NS \\
\hline Previous intra-aortic balloon pump & $10.0 \%(n=5)$ & $4.2 \%(n=68)$ & NS \\
\hline Previous percutaneous intervention & $26.0 \%(n=13)$ & $27.8 \%(n=452)$ & NS \\
\hline
\end{tabular}

$O P C A B$, Off-pump coronary bypass; $N S$, not significant.

TABLE 2A. Timing of conversions

\begin{tabular}{lr}
\hline \multicolumn{1}{c}{ Timing } & Total $(\mathbf{n}=\mathbf{5 0})$ \\
\hline Cardiac manipulation to assess coronary & $10 \%(n=5)$ \\
artery anatomy before commencing grafting & \\
LAD and diagonal artery exposure-grafting & $34 \%(n=17)$ \\
Circumflex artery branches exposure-grafting & $36 \%(n=18)$ \\
Right coronary system exposure-grafting & $6 \%(n=3)$ \\
During-after proximal anastomosis on aorta & $4 \%(n=2)$ \\
Completion of anastomoses-closure of chest & $10 \%(n=5)$
\end{tabular}

$L A D$, Left anterior descending coronary artery.

TABLE 2B. Reason for conversion

\begin{tabular}{lr}
\hline \multicolumn{1}{c}{ Reason } & Total $(\mathbf{n}=\mathbf{5 0})$ \\
\hline Hypotension-ischemia & $76 \%(n=38)$ \\
Bradycardia & $2 \%(n=1)$ \\
Hemorrhage & $8 \%(n=4)$ \\
Ventricular fibrillation & $8 \%(n=4)$ \\
Aortic dissection & $2 \%(n=1)$ \\
Graft occlusion & $4 \%(n=2)$ \\
\hline
\end{tabular}

definition of conversion. ${ }^{7-12}$ We believe that the patients who require conversion to $\mathrm{CPB}$ on an emergency basis for situations like hemodynamic compromise, hemorrhage, ischemic episodes, and cardiac arrest represent true conversions. These are the situations in which conversion to $\mathrm{CPB}$ after attempted OPCAB might be a necessity rather than a choice. However, patients requiring use of $\mathrm{CPB}$ semielectively because of coronary anatomy (eg, diffuse coronary artery disease or intramyocardial vessels) are not true conversions because they depend on the surgeon's preference. Many reports that have shown better short-term outcomes with $\mathrm{OPCAB}$ in comparison with the conventional coronary artery surgery performed with $\mathrm{CPB}$ do not discuss the patients requiring conversions, ${ }^{1-6}$ whereas some briefly mention them but exclude them from the analysis. ${ }^{7,9,10}$ Also, a true estimation of these conversions is difficult to determine because none of these reports studied consecutive patients with intention to treat all patients requiring coronary artery bypass surgery with OPCAB. Our overall incidence of emergency conversion to CPB was $2.97 \%$, which is a true estimate of the problem because our experience consisted of consecutive patients with intention to treat all patients with OPCAB.

Our annual incidence of conversion decreased, which could be explained on the basis of increasing experience of the surgeon, as well as the anesthesiologist. Also, the use of the apical suction cardiac positioning device (Xpose) was introduced in June 2000 for facilitating verticalization of the heart and better exposure of the lateral, inferior, and posterior vessels (Figure 1). Also, as shown in Table 4, use of the Xpose device independently reduced the conversion to CPB on multivariate analysis. However, this analysis did not take the annual incidence of conversion into consideration. Therefore it is likely that the reduction in incidence of conversion to $\mathrm{CPB}$ after the routine use of a cardiac positioning device could be due to the combined effect of the device itself and the increasing experience of the surgical team. Sepic and colleagues ${ }^{13}$ have shown less hemodynamic compromise and better exposure with use of an apical suction device in comparison with deep pericardial sutures alone during beating-heart surgery.

As shown in Table 2, the majority of the conversions occurred during exposure or grafting of the left anterior descending artery system and the circumflex artery system. Because the conversions occurred almost equally during the 
TABLE 3. Postoperative outcomes

\begin{tabular}{|c|c|c|c|}
\hline Variable & $\begin{array}{l}\text { Emergency conversion to } \\
\text { CPB }(n=50)\end{array}$ & $\begin{array}{l}\text { OPCAB without } \\
\text { emergency conversion to } \\
\text { CPB }(n=1628)\end{array}$ & $P$ value \\
\hline Freedom from all complications & $64 \%(n=32)$ & $91.9 \%(n=1483)$ & .0001 \\
\hline Stroke & $6.0 \%(n=3)$ & $1.1 \%(n=18)$ & .02 \\
\hline Transmural myocardial infarction & $2.0 \%(n=1)$ & $0.4 \%(n=7)$ & NS \\
\hline Deep sternal wound infection & $8.0 \%(n=4)$ & $1.5 \%(n=25)$ & .009 \\
\hline Bleeding requiring reoperation & $10.0 \%(n=5)$ & $2.0 \%(n=32)$ & .004 \\
\hline Sepsis & $2.0 \%(n=1)$ & $1.1 \%(n=18)$ & NS \\
\hline GI bleed, perforation, or infarction & $4.0 \%(n=2)$ & $1.4 \%(n=22)$ & NS \\
\hline Renal failure-dialysis & $6.0 \%(n=3)$ & $1.2 \%(n=20)$ & .028 \\
\hline Respiratory failure & $28.0 \%(n=14)$ & $3.7 \%(n=61)$ & .0001 \\
\hline In-hospital mortality & $12.0 \%(n=6)$ & $1.4 \%(n=24)$ & .001 \\
\hline Risk-adjusted mortality & $4.4 \%$ & $1.7 \%$ & NA \\
\hline
\end{tabular}

$C P B$, Cardiopulmonary bypass; $O P C A B$, off-pump coronary artery bypass; $N S$, not significant; $G I$, gastrointestinal.

TABLE 4. Multivariate regression for predictors of emergency conversion to CPB

\begin{tabular}{lccc}
\hline \multicolumn{1}{c}{ Predictor } & Odds ratio & 95\% Confidence limits & P value \\
\hline Left ventricular ejection fraction $<40 \%$ & 1.94 & $0.98-4.02$ & .06 \\
Reoperative surgery & 1.87 & $0.60-5.83$ & .27 \\
Peripheral-cerebrovascular disease & 1.30 & $0.07-2.42$ & .39 \\
Priority of the operation & 1.55 & $0.89-3.41$ & .09 \\
Diabetes mellitus & 1.07 & $0.59-1.94$ & .80 \\
Renal failure & 10.29 & $0.43-242$ & .14 \\
Preoperative intra-aortic balloon pump & 1.91 & $0.68-5.33$ & .21 \\
Previous myocardial infarction & 1.92 & $0.89-4.02$ & .09 \\
Previous percutaneous coronary intervention & 0.89 & $0.45-1.75$ & .73 \\
Use of Xpose for verticalization & 0.49 & $0.26-0.91$
\end{tabular}

$C P B$, Cardiopulmonary bypass.

surgical intervention on both vessel systems, hemodynamic compromise during displacement of the heart (verticalization) did not seem to be the only factor responsible for conversion. There was less incidence of conversion during right coronary artery grafting. The order of grafting in the majority of the patients was left coronary artery system first, followed by right coronary artery grafting. Therefore in a majority of the patients, adequate perfusion of the myocardium was already established while the right coronary artery was occluded for grafting.

Yeatman and coworkers ${ }^{14}$ and D' Ancona and associates $^{15}$ have shown a reduction in transient intraoperative myocardial dysfunction and myocardial stunning during $\mathrm{OPCAB}$ using intracoronary shunts. The majority of our patients required conversions because of ischemia-related hypotension, ventricular fibrillation, and bradycardiac arrest during vessel occlusion for bypass grafting. Only one of these patients had an intracoronary shunt used. Although we do not have data on the use of intracoronary shunts in nonconverted patients (because it was not part of our data- set), it is highly likely that ischemia-related conversions could have been reduced by the use of intracoronary shunts.

Cardiac arrest requiring cardiopulmonary resuscitation occurred in $30 \%$ of our conversions. Most of the major adverse outcomes were in this group of patients. Although we have a policy of the perfusion staff remaining on standby with a primed $\mathrm{CPB}$ circuit for all OPCAB procedures, the average time from arrest to establishing $\mathrm{CPB}$ could be further reduced by using a cannulation system, which is rapid to install. Developing a self-retaining cannula, which can be inserted with a single stab without the need for purse-string sutures, might be the way forward.

In our experience emergency conversion to $\mathrm{CPB}$ is unpredictable because it can occur at any stage of the operation. As shown from multivariate regression analysis, none of the major preoperative risk factors were independent predictors of conversion. Converted patients had a significantly higher prevalence of poor ventricular function. Poor ejection fraction was almost a significant predictor on multivariate analysis. Patients with poor left ventricular ejection 
fraction are less likely to tolerate transient ischemia and verticalization, leading to higher conversion rates.

The most important finding of our study is the significantly increased major morbidity and mortality associated with emergency conversion. Almost one third of the converted patients had cardiac arrest, and a significantly higher number of patients had a period of hypotension and low cardiac output. The surprising finding was a lower incidence of transmural myocardial infarction in converted patients, which might explain transient ischemia as the root cause of most conversions.

These unfavorable outcomes have major implications on the validity of previous retrospective comparison between OPCAB and on-pump coronary artery bypass grafting. ${ }^{1-4}$ Many of these reports identify patients undergoing OPCAB from the data set as patients having a CPB time of zero and thus end up assigning converted patients to the on-pump group, leading to an unfair comparison. This bias can be eliminated by a prospective randomized study with intention-to-treat analysis after randomization, as shown by Van Dijk and coworkers. ${ }^{16}$

In conclusion, an emergency conversion to $\mathrm{CPB}$ during attempted OPCAB results in a significantly higher morbidity and mortality. Studies comparing OPCAB with conventional coronary artery bypass surgery should include converted patients in the OPCAB group to eliminate bias. In our experience emergency conversion to $\mathrm{CPB}$ is an unpredictable event. The incidence of conversion decreases with the increasing experience of surgeons in performing $\mathrm{OPCAB}$ and the use of a cardiac positioning device.

\section{References}

1. Magee MJ, Jablonski KA, Stamou SC, Pfister AJ, Dewey TM, Dullum MK, et al. Elimination of cardiopulmonary bypass improves early survival for multivessel coronary artery bypass patients. Ann Thorac Surg. 2002,73:1196-203.

2. Cleveland JC, Shroyer AL, Chen AY, Peterson E, Grover FL. Offpump coronary artery bypass grafting decreases risk-adjusted mortality and morbidity. Ann Thorac Surg. 2001;72:1282-8.

3. Plomondon ME, Cleveland JC, Ludwig ST, Grunwald GK, Kiefe CI, Grover FL, et al. Off-pump coronary artery bypass is associated with improved risk-adjusted outcomes. Ann Thorac Surg. 2001;72:114-9.

4. Hart JC, Spooner TH, Pym J, Flavin TF, Edgerton JR, Mack MJ, et al. A review of 1582 consecutive Octopus off-pump coronary bypass patients. Ann Thorac Surg. 2000;70:1017-20.

5. Hernandez F, Cohn WE, Baribeau YR, Tryzelaar JF, Charlesworth DC, Clough RA, et al. In-hospital outcomes of off-pump versus on-pump coronary artery bypass procedures: a multicenter experience. Ann Thorac Surg. 2001;72:1528-34.

6. Patel NC, Deodhar AP, Grayson AD, Pullan DM, Keenan DJ, Hassan $\mathrm{R}$, et al. Neurological outcomes in coronary surgery: independent effect of avoiding cardiopulmonary bypass. Ann Thorac Surg. 2002; 74:400-5.

7. Sabik JF, Gillinov AM, Blackstone EH, Vacha C, Houghtaling PL, Navia J, et al. Does off-pump coronary surgery reduce morbidity and mortality? J Thorac Cardiovasc Surg. 2002;124:698-707.

8. Kshettry VR, Flavin TF, Emery RW, Nicoloff DM. Does multivessel off-pump coronary artery bypass reduce postoperative morbidity? Ann Thorac Surg. 2000;69:1725-31.
9. Kavarana MN, Asher AS, Barbone A, Williams MR, Faber JM, Weinberg $\mathrm{AD}$, et al. A comparison of consecutive off-pump versus conventional coronary artery bypass. Heart Surg Forum. 2001;4:160-5

10. Patel NC, Pullan DM, Fabri BM. Does off-pump total arterial revascularisation without aortic manipulation influence neurological outcomes? A study of 226 consecutive, unselected cases. Heart Surg Forum. 2002;5:28-32.

11. Czerny M, Baumer H, Kilo J, Zuckermann A, Grubhofer G, Chevtchik $\mathrm{O}$, et al. Complete revascularization in coronary artery bypass grafting with and without cardiopulmonary bypass. Ann Thorac Surg. 2001; 71:165-9.

12. Iaco AL, Contini M, Teodori G, Di Mauro M, Di Giammarco G, Vitolla G, et al. Off or on bypass: what is the safety threshold? Ann Thorac Surg. 1999;68:1486-9.

13. Sepic J, Wee JO, Soltesz EG, Hsin MK, Cohn LH, Lawrence RG, et al. Cardiac positioning using an apical suction device maintains beating heart hemodynamics. Heart Surg Forum. 2002;5:279-84.

14. Yeatman M, Caputo M, Narayan P, Gosh AK, Ascione R, Angelini GD. Intracoronary shunts reduce transient intraoperative myocardial dysfunction during off-pump coronary operations. Ann Thorac Surg. 2001;73:1411-7.

15. D'Ancona G, Donias HW, Bergsland J, Karamanoukian HL. Myocardial stunning after off-pump coronary artery grafting. Safeguards and pitfalls. Ann Thorac Surg. 2001;72:2182-3.

16. Van Dijk D, Nierich AP, Jansen EW, Nathoe HM, Suyker WJ, Diephuis JC, et al. Early outcome after off-pump versus on-pump coronary bypass surgery. Results from a randomized study. Circulation. 2001;104:1761-6.

\section{Discussion}

Dr Irving L. Kron (Charlottesville, $\mathrm{Va}$ ). I very much enjoyed the paper by Patel and colleagues from Lenox Hill. They discussed a very important but little-studied issue. They studied nearly 2000 patients who intended to be treated with OPCAB. Just about $3 \%$ of the patients required urgent conversion. The mortality for the off-pump procedure was $1.4 \%$. However, those patients who underwent emergency conversion had a $12 \%$ mortality and a much higher morbidity. The authors' key point, which is the most important aspect, is that patients who are urgently converted to coronary bypass in comparison of off-pump with on-pump bypass are often counted in the on-pump group. This is clearly unfair to the on-pump analysis, and intention to treat, as the authors have concluded, is an important point.

The major question for the authors is why there is such a high mortality and conversion to on-pump procedures. At our institution, the raw mortality for on-pump coronary bypass was $1.6 \%$ last year, including all comers. Clearly, many have demonstrated that elective bypass with an on-pump procedure has a reasonably low mortality. It is still legal in the United States to use the pump for these procedures.

This leads me to wonder the following: when patients get into real difficulty, bypass here might have been too late, and the question, the real question for the authors is how one can have one's cake and eat it too. Are there any specific points at which you could have recognized that you were going down a bad road and made a difference by going to on-pump bypass a little bit earlier? That is really the biggest issue for you, and I am sure you have looked at this.

Finally, how often did elective conversion occur, and what were the results there?

Dr Patel. Thank you very much, Dr Kron. I will answer your second question first. The elective conversions during this expe- 
rience occurred in 44 patients, almost the same number. When we looked at the subanalysis of that, there was no difference in the outcomes in those patients compared with those of the other patients.

Coming to the point, when things go wrong during emergency conversion, they happen very quickly, and the patients become very sick. That is the reason why these bad outcomes occur. Now, what we have to trust is that we have to identify some intraoperative monitoring of myocardial ischemia, some kind of monitoring, $\mathrm{pH}$ continuous monitoring, which will identify and tell us much earlier that we should convert before it is too late, and that is what will help us improve our outcomes for these patients. Probably we are pushing them too much and we should convert them earlier, and then we will not have the same results as our elective conversions, which are pretty good results.

Dr Michael J. Mack (Dallas, Tex). I would like to congratulate the Lenox Hill group for their work in this area.

Dr Edgerton from our group presented our experience with the same issue at the Southern Thoracic Surgery meeting in November (Ann Thorac Surg 2003;76:1138-11), but the findings are virtually the same. Our conversion rate overall was $3.7 \%$, which included both elective and urgent conversions. However, when we performed our analysis, we compared our conversion rate with our on-pump group rather than our off-pump group, asking the question of whether there are patients that are potentially being hurt by being started off-pump as opposed to being started on-pump and whether we could identify those patients and not treat them offpump. Therefore, my first question is as follows: why are you comparing the converted patients with your off-pump series rather than your on-pump group?

Second, we were able to find predictors of conversion, and they included surgeon experience, reoperative procedures, and patients with a history of congestive heart failure. I noticed that in your logistic regression you did not include surgeon experience as one of the variables in the equation. My second question is as follows: because surgeon experience changed over the years, and not just the addition of a positioner, did that play a role in your conversions?
You have already answered my third point, but we found that all of our mortality, which was $18 \%$, occurred in patients who were converted urgently and not electively. In other words, if you could not find a vessel or you judged the disease to be too severe to bypass, there was no mortality in the group that was converted for that reason. We have found the same thing; that is, if there is the least bit of instability at all, our threshold for conversion is immediate before one gets too far down the line.

Dr Patel. Answering your first question, as to why I did not compare with on-pump patients, this is a contemporary series. These are consecutive patients, all of them with intention to treat with off-pump bypass. Therefore, I tried to match them with what our intentions to treat these patients were. Forty-four patients during that same time frame underwent on-pump bypass, but they were all elective conversions, and we did not see a difference. That is why I compared them with what we set out to treat these patients with, and that is our main message, as Dr Kron pointed out. As to your second question, these patients were operated on by essentially 2 senior surgeons and 2 intermediate-level surgeons. I quite agree that we did not look at a specific surgeon in our multivariate model, but I doubt that would make much difference because the majority of procedures were performed by 2 very experienced surgeons.

Dr Joan Ivanov (Toronto, Ontario, Canada). This was a wonderfully interesting presentation. It appeared from the methods for your multivariable model that you used a maineffects model only. It also appeared from the graphics (this continues on with the previous question) that there was a temporal change in your experience. Therefore, might I suggest to you that the risk reduction you observed with the Xpose device might have been confounded with a temporal experience? Also, you probably should have used an interaction between time and the device to get a true idea of the risk reduction associated with the Xpose device.

Dr Patel. I could not agree less with you. I think it could be that there is a confounding variable of time related to our analysis with that. I think if you use time, perhaps the Xpose device might not be an important factor. 